\title{
Retrieving the global distribution of the threshold of wind erosion from satellite data and implementing it into the Geophysical Fluid Dynamics Laboratory land-atmosphere model (GFDL AM4.0/LM4.0)
}

Bing Pu et al.

Correspondence to: Bing Pu (bing.pu@noaa.gov)

The copyright of individual parts of the supplement might differ from the CC BY 4.0 License. 


\section{Supplement}

Table S1 Name and location of 16 RSMAS sites used in Figure 9.

\begin{tabular}{cccc}
\hline No. & Sites & Lat/Long & Record length (year) \\
\hline 1 & Cape Grim & $40.68^{\circ} \mathrm{S}, 144.68^{\circ} \mathrm{E}$ & 14 \\
2 & Marsh & $62.18^{\circ} \mathrm{S}, 58.3^{\circ} \mathrm{W}$ & 7 \\
3 & Mawson & $67.6^{\circ} \mathrm{S}, 62.5^{\circ} \mathrm{E}$ & 10 \\
4 & Palmer Station & $64.77^{\circ} \mathrm{S}, 64.05^{\circ} \mathrm{W}$ & 7 \\
5 & Norfolk Island & $29.08^{\circ} \mathrm{S}, 167.98^{\circ} \mathrm{E}$ & 14 \\
6 & American Samoa & $14.25^{\circ} \mathrm{S}, 170.58^{\circ} \mathrm{W}$ & 13 \\
7 & Midway Island & $28.22^{\circ} \mathrm{N}, 177.35^{\circ} \mathrm{W}$ & 16 \\
8 & Oahu Hawaii & $21.33^{\circ} \mathrm{N}, 157.7^{\circ} \mathrm{W}$ & 15 \\
9 & Cheju\Korea\Pem & $33.52^{\circ} \mathrm{N}, 126.48^{\circ} \mathrm{E}$ & 4 \\
10 & Fanning Island & $3.92^{\circ} \mathrm{N}, 159.33^{\circ} \mathrm{W}$ & 5 \\
11 & Ragged Point & $13.17^{\circ} \mathrm{N}, 59.43^{\circ} \mathrm{W}$ & 14 \\
12 & Izaña Tenerife & $28.3^{\circ} \mathrm{N}, 16.5^{\circ} \mathrm{W}$ & 11 \\
13 & Bermuda West \& East & $32.27^{\circ} \mathrm{N}, 64.87^{\circ} \mathrm{W}$ & 9 \\
14 & Heimaey Iceland & $63.4^{\circ} \mathrm{N}, 20.3^{\circ} \mathrm{W}$ & 7 \\
15 & Mace Head & $53.32^{\circ} \mathrm{N}, 9.85^{\circ} \mathrm{W}$ & 6 \\
16 & RSMAS & $25.75^{\circ} \mathrm{N}, 80.25^{\circ} \mathrm{W}$ & 10 \\
\hline
\end{tabular}


Table S2 Annual mean dust emission $\left(\mathrm{Tg} \mathrm{yr}^{-1}\right)$ averaged over nine regions and global land from the Control, $\mathrm{V}_{\text {thresh }} \mathrm{Ann}$, and $\mathrm{V}_{\text {thresh }} 12 \mathrm{mn}$ simulations.

\begin{tabular}{cccc}
\hline Regions & Control & $\mathbf{V}_{\text {thresh }} \mathbf{A n n}$ & $\mathbf{V}_{\text {thresh }} \mathbf{1 2 m n}$ \\
\hline Sahel & 148 & 1185 & 970 \\
Sahara & 216 & 487 & 488 \\
Arabian Peninsula & 130 & 536 & 482 \\
Northern China & 74 & 78 & 73 \\
India & 55 & 438 & 239 \\
US & 4 & 78 & 37 \\
South Africa & 8 & 12 & 7 \\
South America & 25 & 169 & 103 \\
Australia & 44 & 556 & 434 \\
Global land & 978 & 5190 & 3562 \\
\hline
\end{tabular}


One grid point in the U.S. $(34.5 \mathrm{~N}, 105 \mathrm{~W})$

(a) Cumulative Frequency of DOD

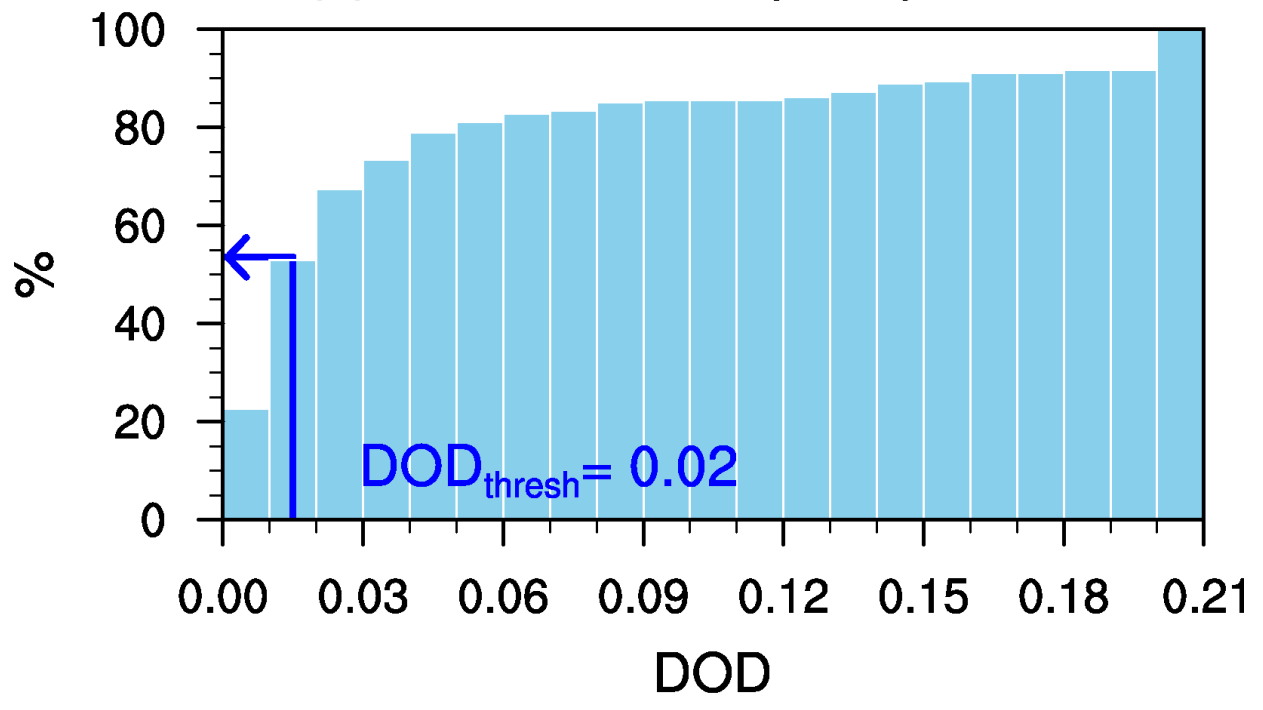

(b) Cumulative Frequency of $\mathrm{V}_{10 \mathrm{~m}}$

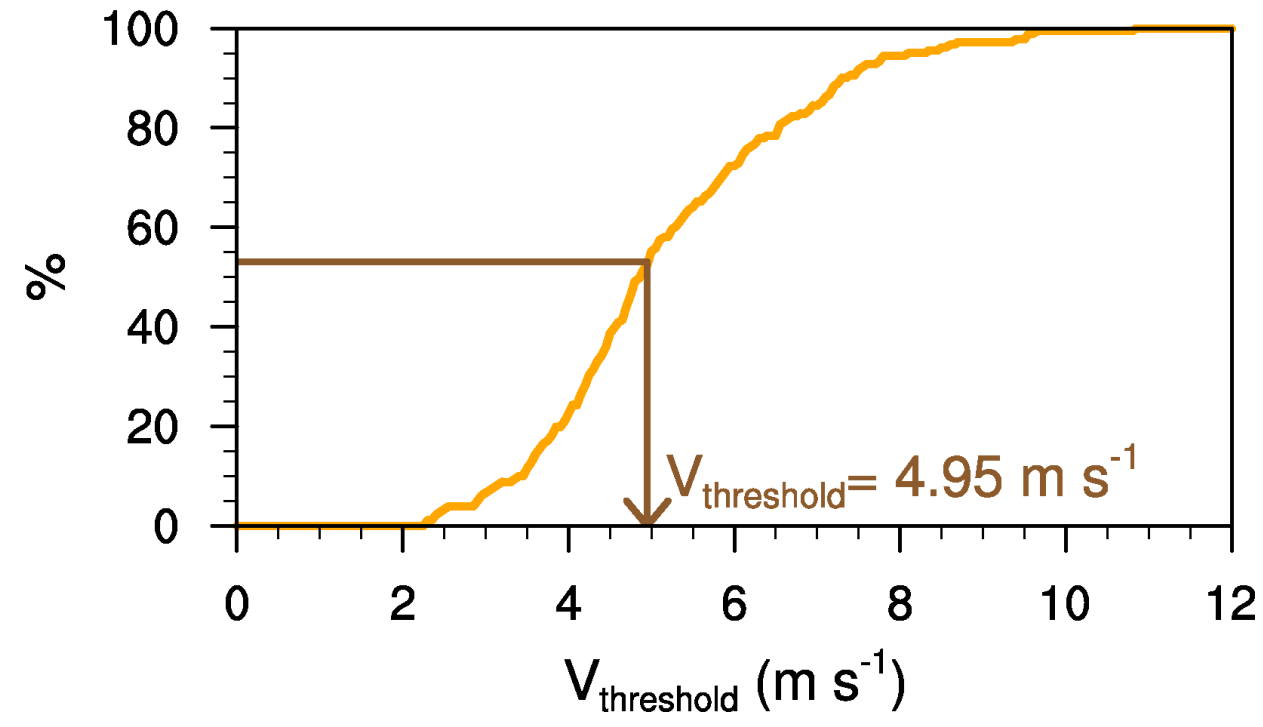

Figure S1. A schematic of deriving $V_{\text {threshold }}$ at one grid point in the U.S. in March. (a) Determining the threshold percentage of cumulative frequency of DOD at $D O D_{\text {thresh }}=$ 0.02 level; (b) matching the threshold percentage in (a) with the percentage of cumulative frequency distribution of surface wind speed to get the threshold of wind erosion. 


\section{Dust source function}
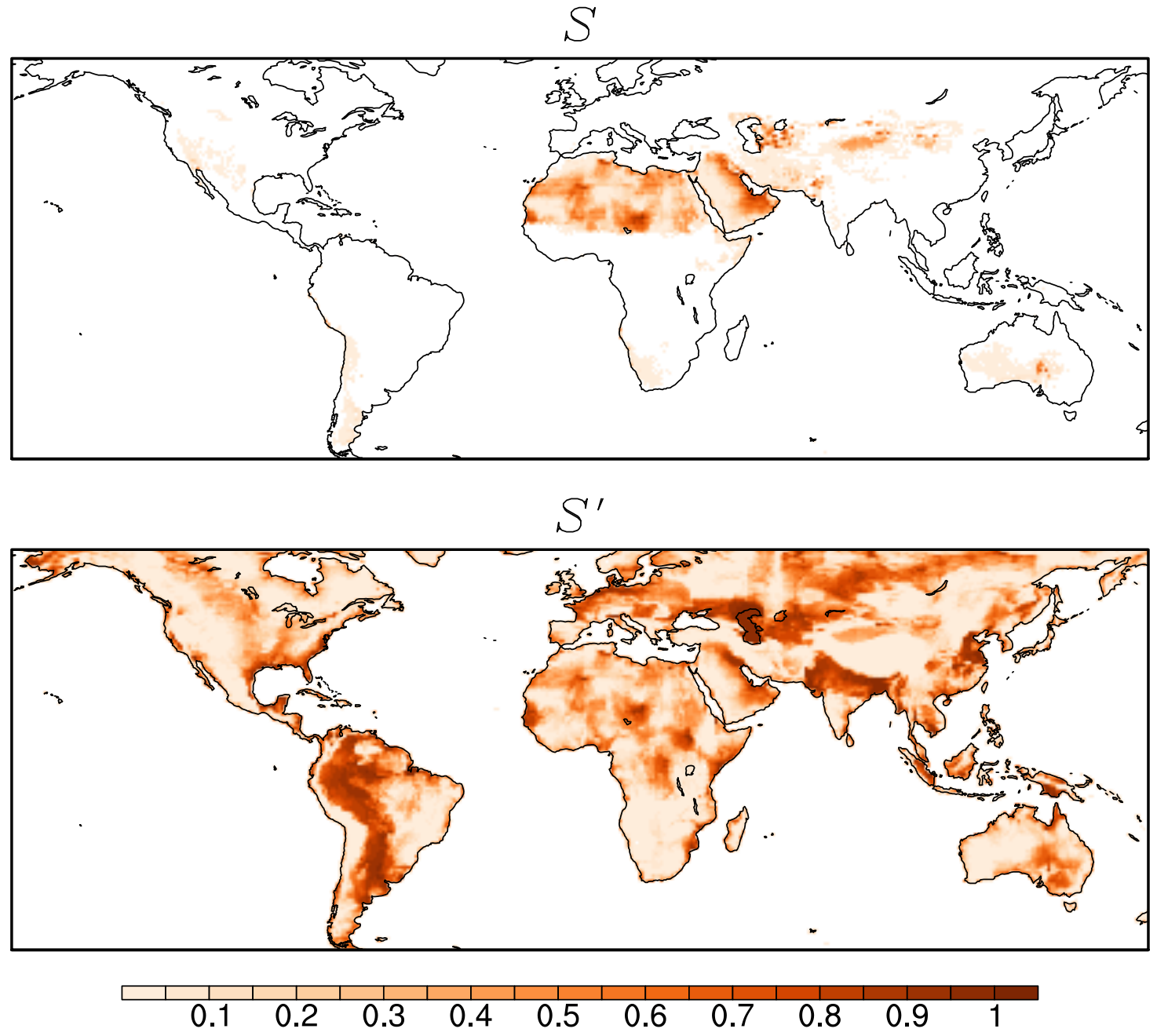

Figure S2. Dust source function $S$ in Eq. 4 used in the Control simulation (top) and

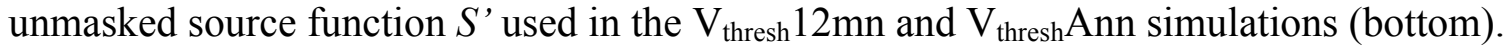




\section{LAI $\mathrm{V}_{\text {thresh }} 12 \mathrm{mn}(2001-2015)$}

(a) DJF

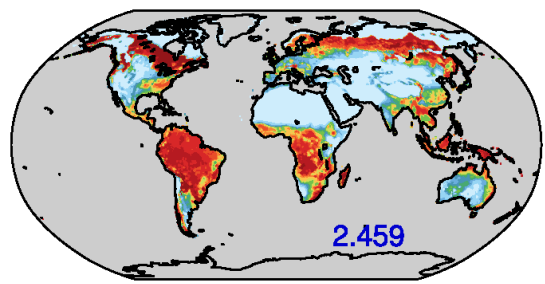

(c) JJA
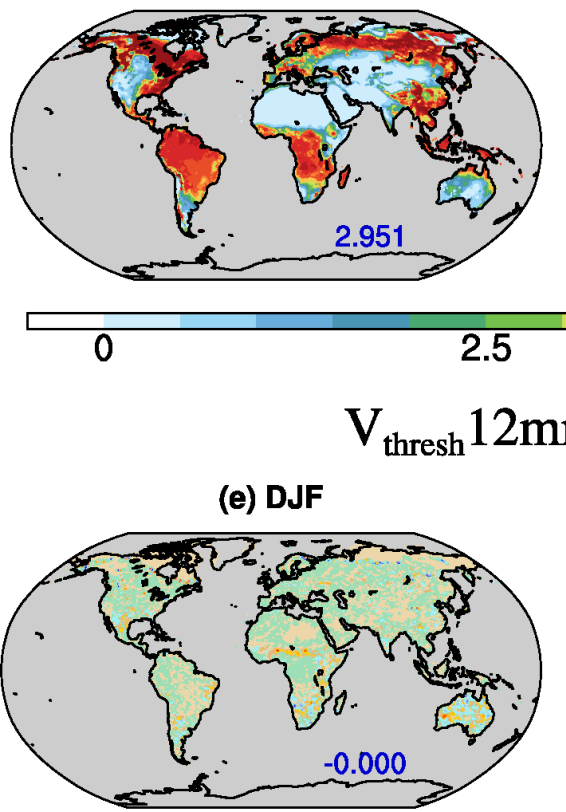

(g) JJA
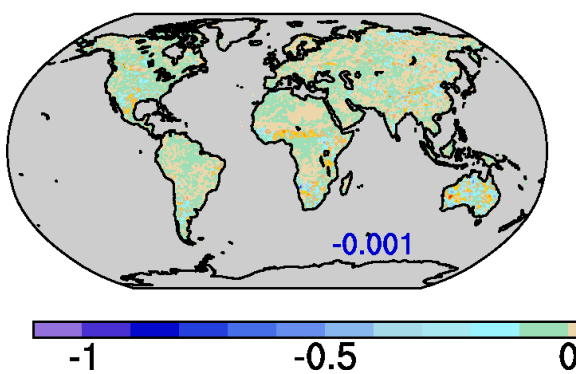

(b) MAM

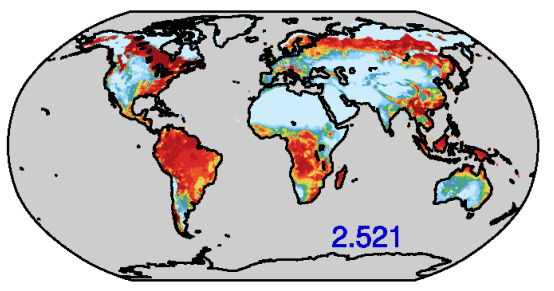

(d) SON

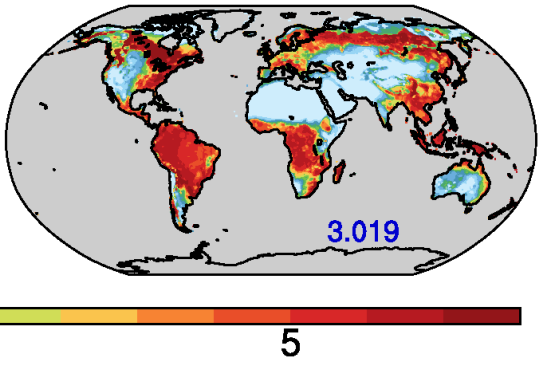

5 (f) MAM

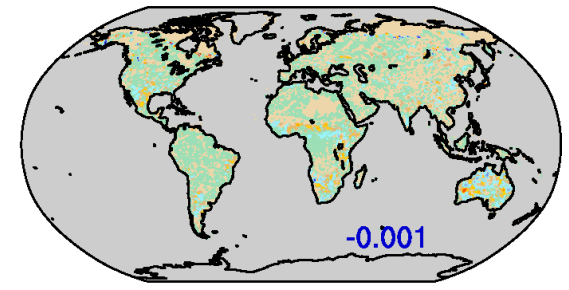

(h) SON

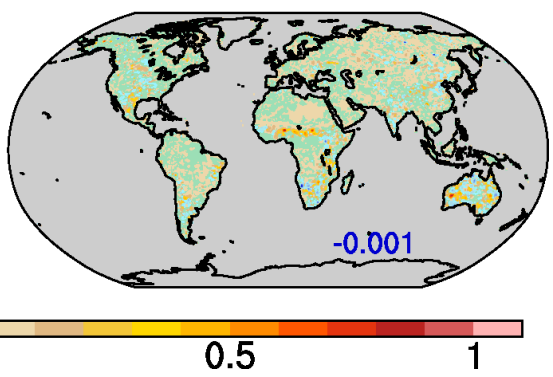

Figure S3. (a)-(d) Model simulated LAI from the $\mathrm{V}_{\text {thresh }} 12 \mathrm{mn}$ run, average from 2001 to 2015 for four seasons. (e)-(h) The difference between the $V_{\text {thresh }} 12 \mathrm{mn}$ run and the Control run. Global land averages are listed at the bottom of each plot. 
LAI $\mathrm{V}_{\text {thresh }}$ Ann (2001-2015)

(a) DJF

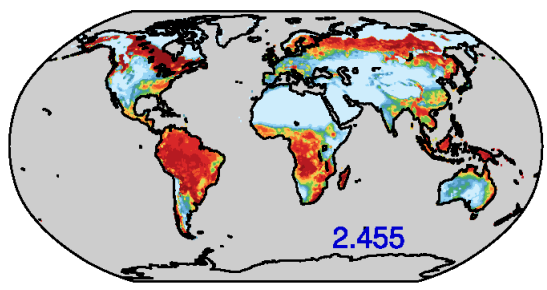

(c) JJA
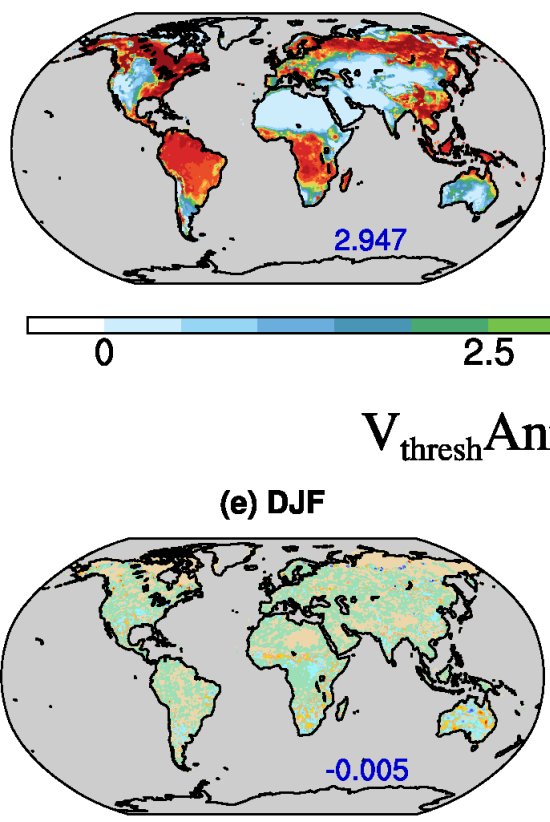

(g) JJA

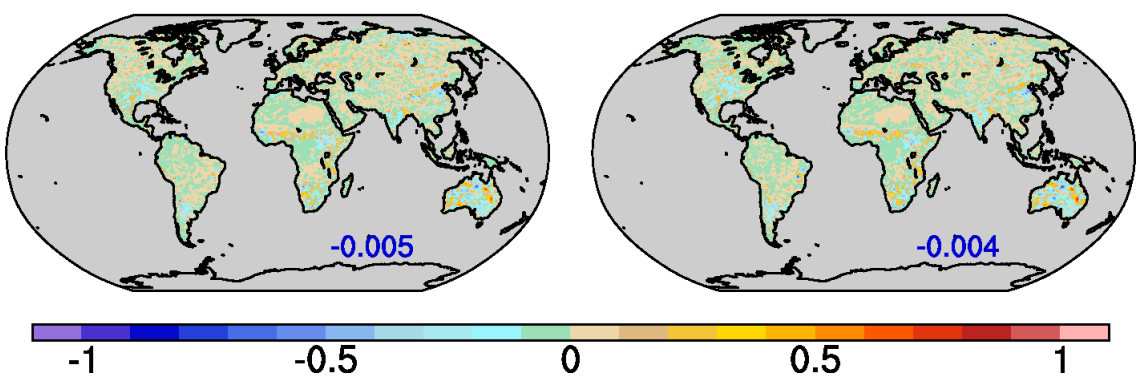

Figure S4. Same as Fig. S3, but for the $\mathrm{V}_{\text {thresh }} \mathrm{Ann}$ simulation.

(b) MAM

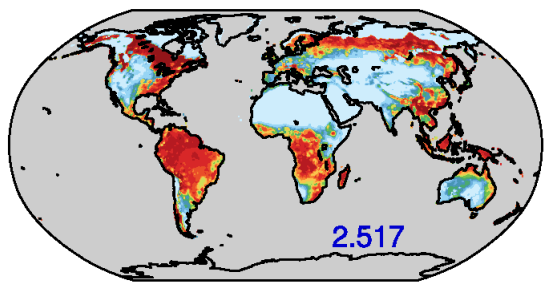

(d) SON

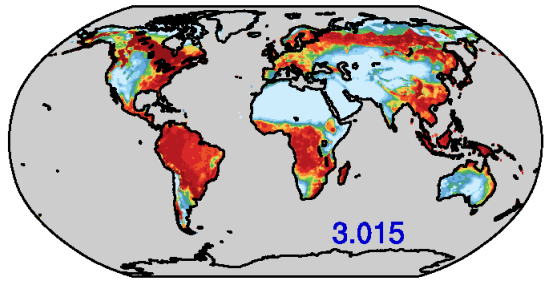

5

(f) MAM

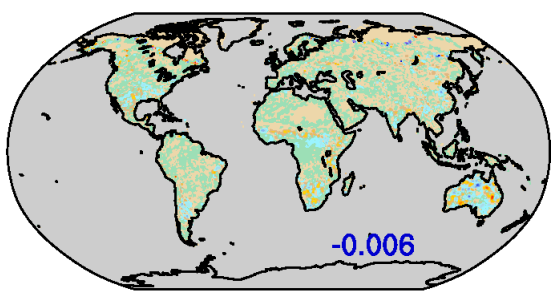

(h) SON 

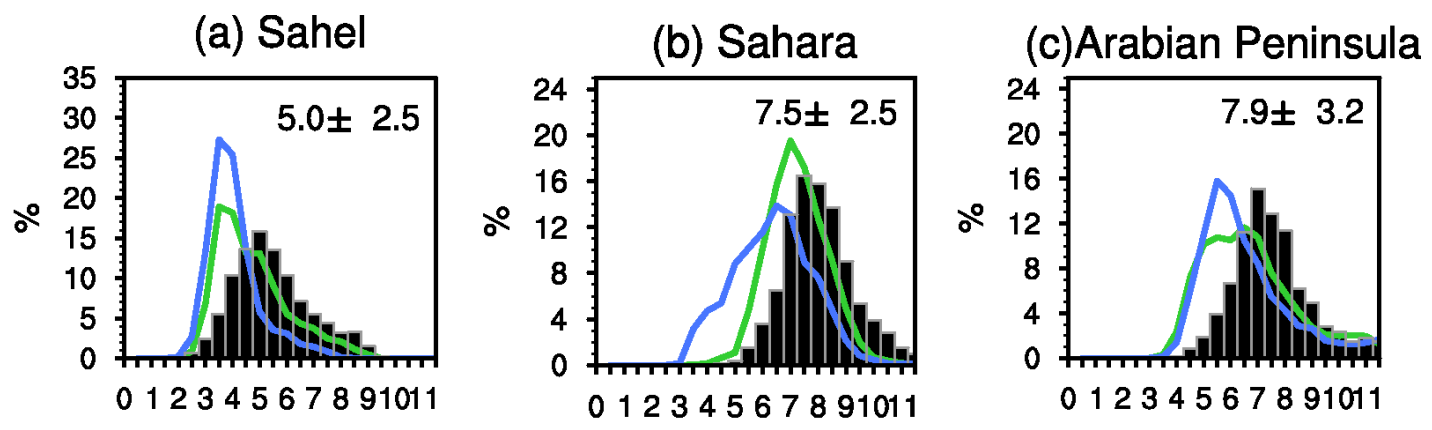

(d) N. China

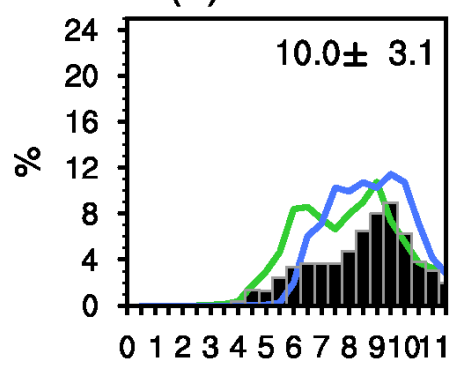

(e) India

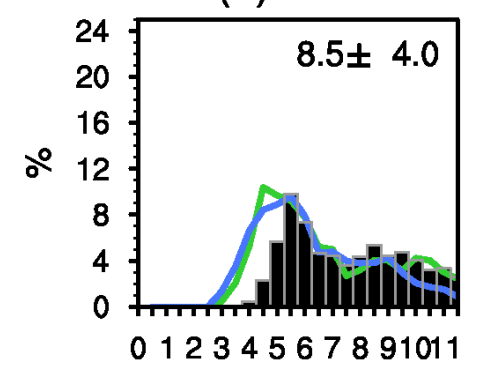

(f) US

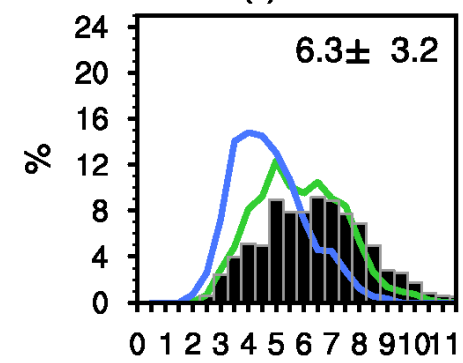

(g) S. Africa

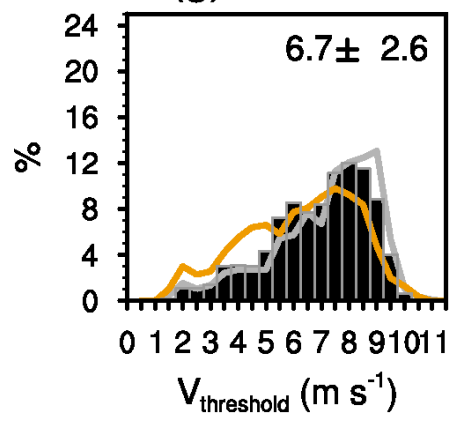

(h) S. America
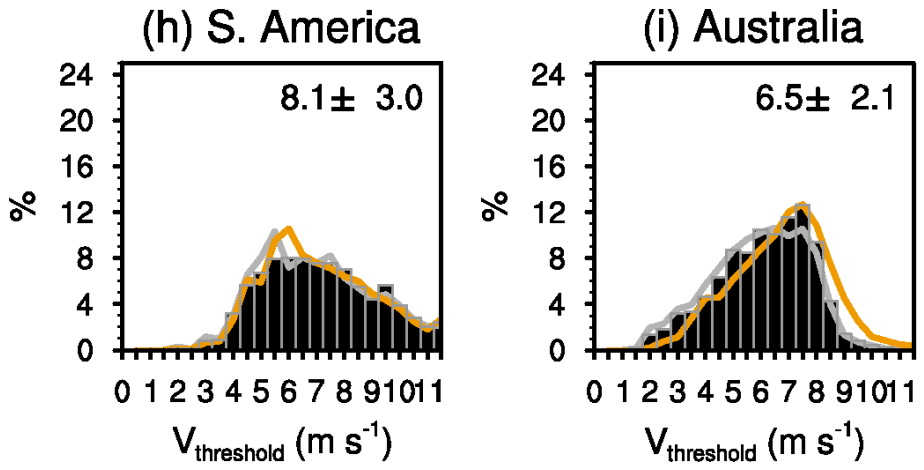

Figure S5. Same as Fig. 2 but for $V_{\text {threshold }}$ using $D O D_{\text {thresh }}=0.5$ or 0.05 . 
(a) Record length of AERONET AOD (550 $\mathrm{nm}$ )

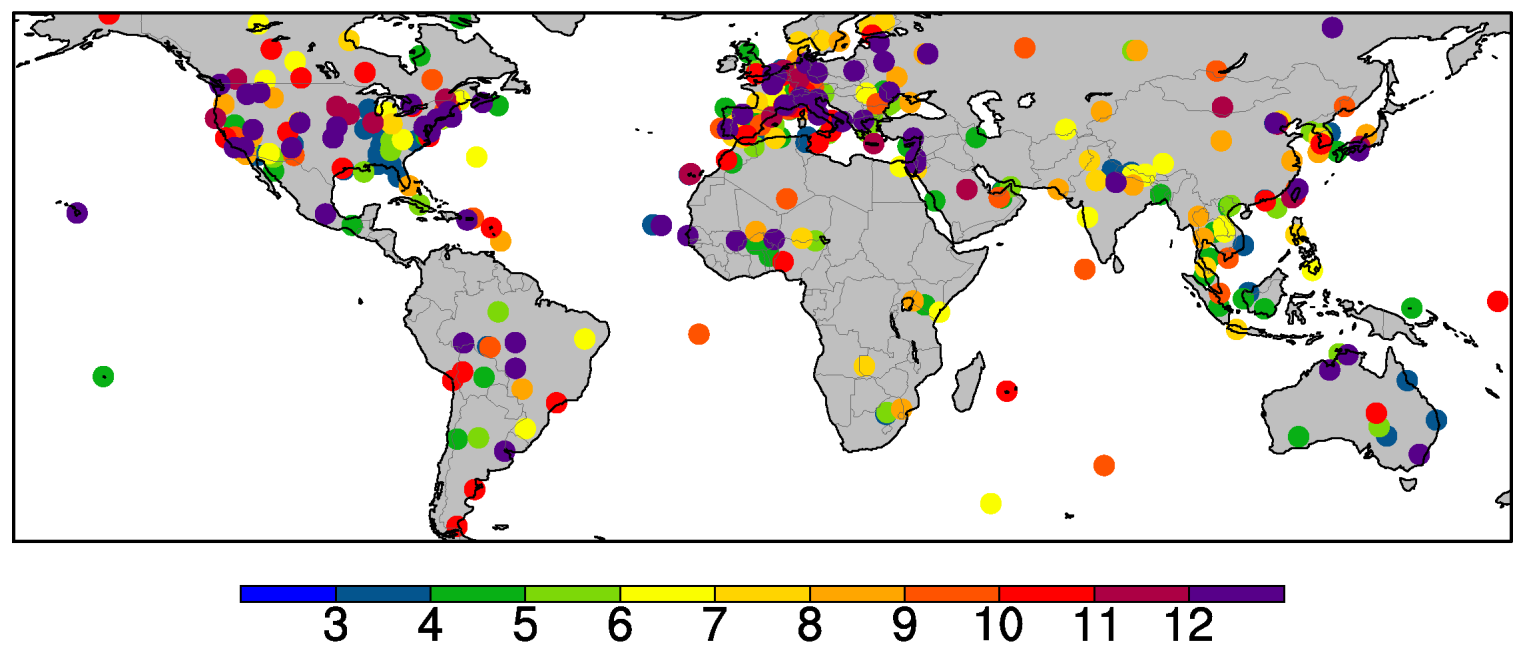

(b) Record length of AERONET SDA COD (500nm)

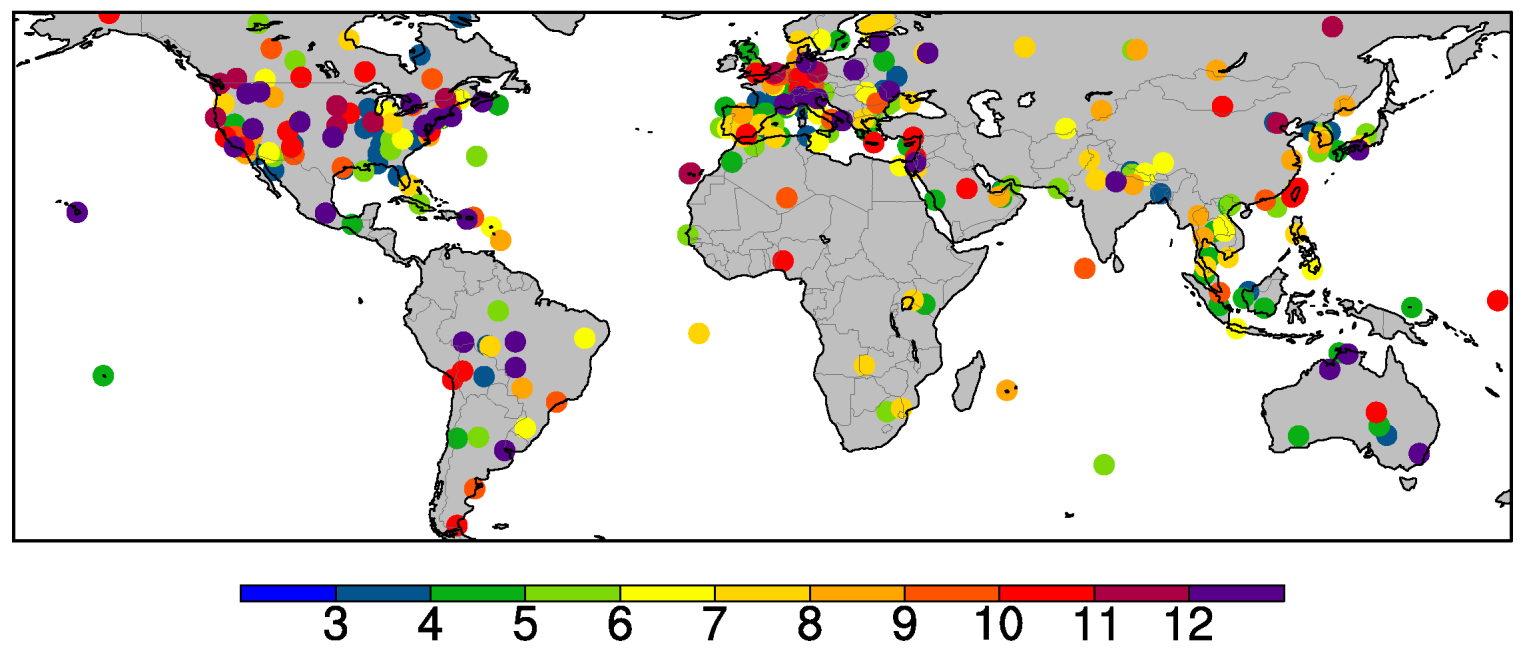

Figure S6. Length of records (year) for AERONET (a) AOT stations and (b) SDA COD stations used in Figs. 5-6. 


\section{AERONET SDA sites (N. Africa)}
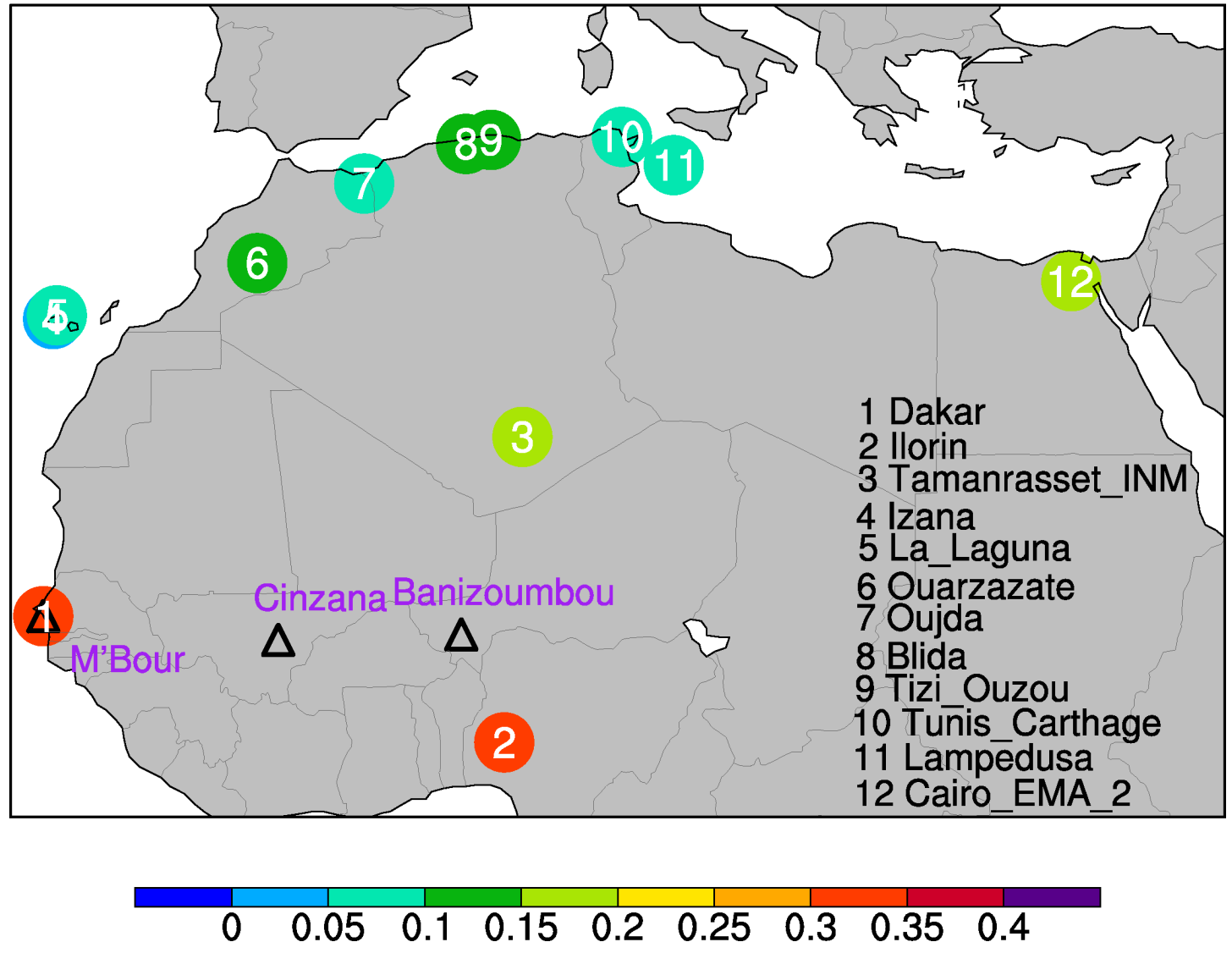

Figure S7. Location of 12 AERONET SDA COD sites (filled circles with site numbers) and three LISA sites (black triangles with site names in purple). For SDA site, the filled color indicates the climatological values of COD during 2003-2015, and the names of the sites are listed on the right corner of the plot. 


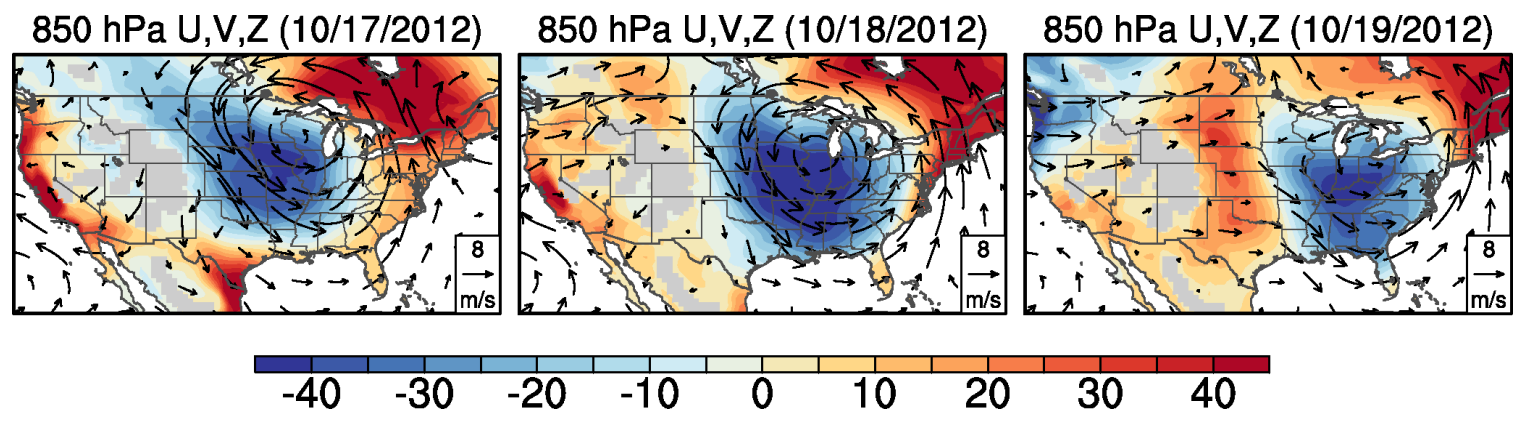

Figure S8. Daily anomalies (with reference to the 2000-2015 mean) of $850 \mathrm{hPa}$ geopotential height (gpm; only values over land are plotted) and wind vectors $\left(\mathrm{m} \mathrm{s}^{-1}\right)$ from Oct. 17 to Oct. 19, 2012 from the $\mathrm{V}_{\text {thresh }} 12 \mathrm{mn}$ simulation. Elevations higher than $850 \mathrm{hPa}$ are masked in grey. 

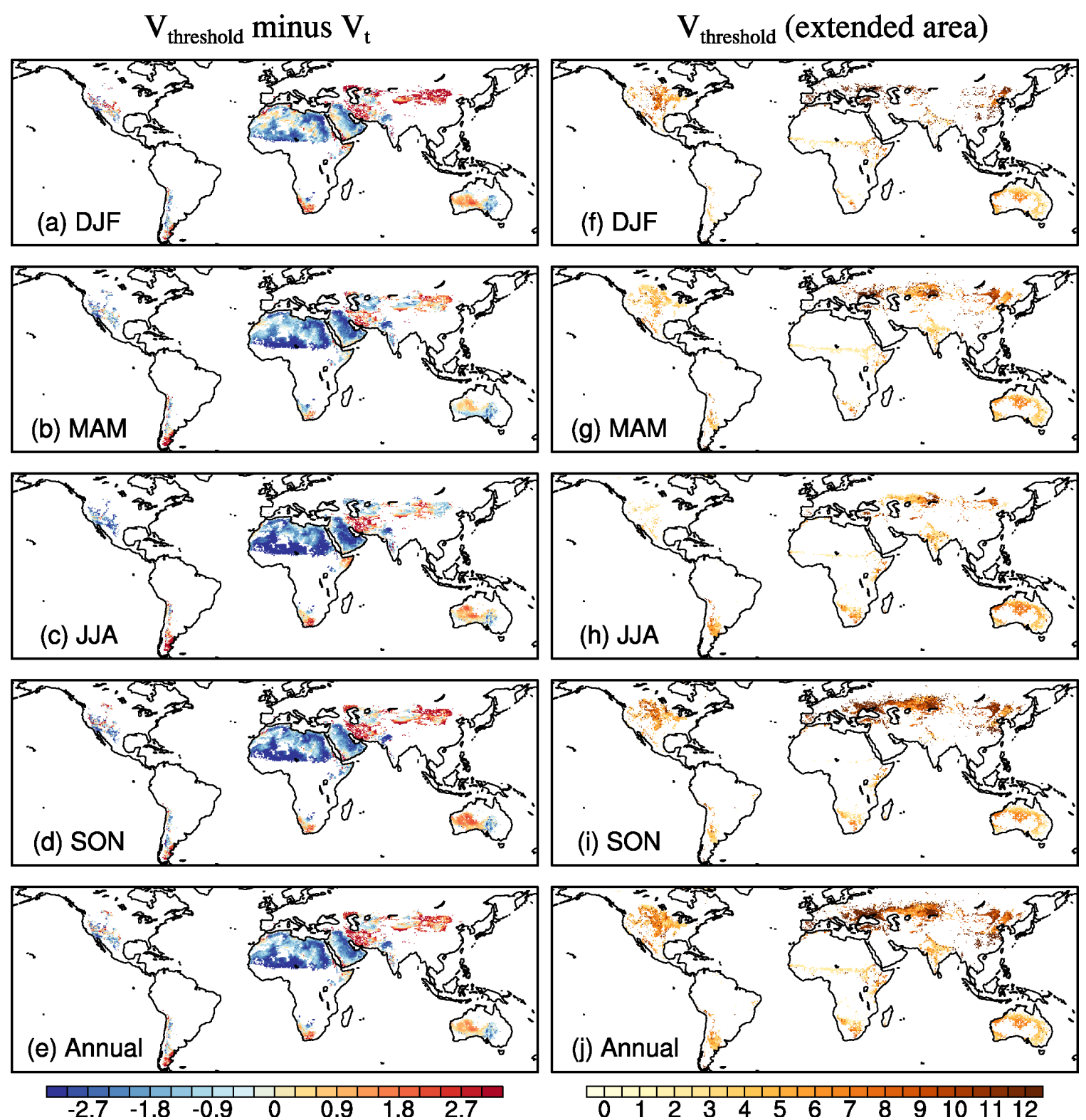

\begin{tabular}{lllllllllllll}
\hline 0 & 1 & 2 & 3 & 4 & 5 & 6 & 7 & 8 & 9 & 10 & 1112
\end{tabular}

Figure S9. (a)-(e) The differences between the $V_{\text {threshold }}$ and default $V_{t}$ (i.e., $V_{t}=6 \mathrm{~m} \mathrm{~s}^{-1}$ in Eq. 4) in the AM4.0/LM4.0. (f)-(j) $V_{\text {threshold }}$ over the area extend beyond the domain of the default dust source function $(S)$. Unit: $\mathrm{m} \mathrm{s}^{-1}$. 

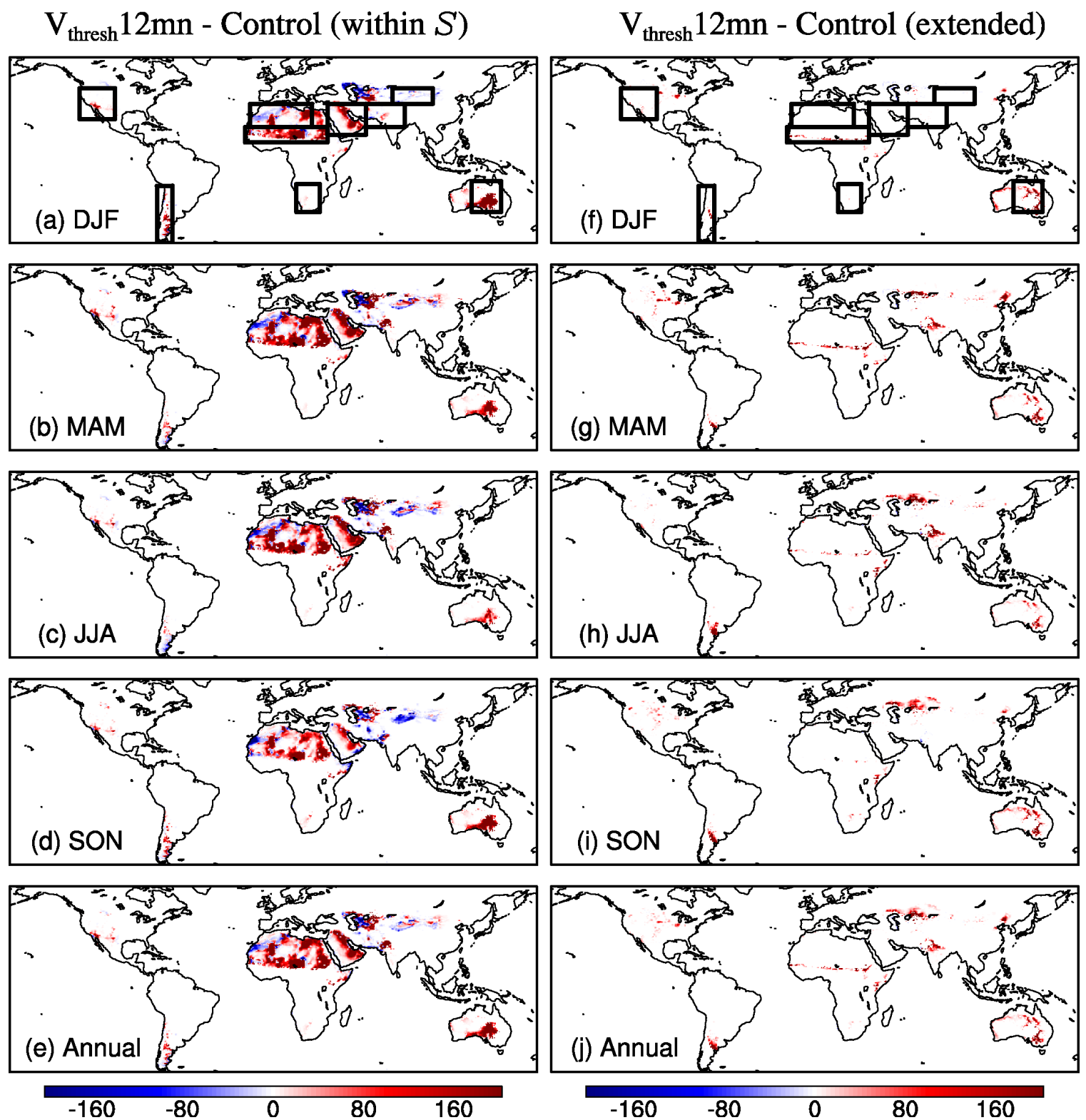

Figure S10. The differences of dust emission $\left(\mathrm{g} \mathrm{m}^{-2} \mathrm{yr}^{-1}\right)$ between the $\mathrm{V}_{\text {thresh }} 12 \mathrm{mn}$ and Control runs are decomposed into two parts: (a)-(e) within the domain of the default dust source function $(S)$ and (f)-(j) over the extended area outlined by $V_{\text {threshold. }}$. Black boxes denote nine dust source regions as listed in Table 1. 